TAO, Vol. 15, No. 3, 503-521, September 2004

\title{
Possibility of Forecasting Aftershock Distributions from Stress Change: A Case Study of Inland Taiwan Earthquakes
}

\author{
Chung-Han Chan ${ }^{1, *}$ and Kuo-Fong $\mathrm{Ma}^{1}$ \\ (Manuscript received 30 March 2004, in final form 1 July 2004)
}

\begin{abstract}
Spatial heterogeneous slip dislocation models from seismic waveform inversions of several moderate to large earthquakes in the past decade in the Taiwan area are used to calculate stress transfer conditions associated with aftershock distributions. Regardless of the possibility of aftershocks along different fault planes to the mainshock, stress change calculations for optimum orientation planes after the mainshock show a great degree of consistency in positive stress change to aftershock distribution. Toward the possibility of forecasting aftershock distributions from stress changes due to the mainshock, we considered homogeneous fault models on the basis of earthquake scaling law to produce rapid stress change calculations. Stress changes from homogeneous and heterogeneous fault models show similar patterns. They both show good correlation with aftershock distributions, even for the complex fault rupture of the 1999 Chi-Chi, Taiwan, earthquake. Our results, thus, support the possibility of forecasting aftershock distributions using mainshock stress changes. Once the location, magnitude and focal mechanism of an earthquake become available, stress change calculations can be carried out to forecast aftershock distribution for earthquake hazard mitigation.
\end{abstract}

(Key words: Coulomb stress change, Scaling law, Da-Pu earthquake,

Nan-Ao earthquake, Ruey-Li earthquake, Chi-Chi earthquake,

Chia-Yi earthquake)

\footnotetext{
${ }^{1}$ Institute of Geophysics, National Central University, Chung-Li, Taiwan, ROC

* Corresponding author address.Dr. Chung-Han Chan, Institute of Geophysics, National Central University, Chung-Li, Taiwan, ROC; E-mail: han@eqkc.earth.ncu.edu.tw
} 


\section{INTRODUCTION}

Large earthquakes yield loss of life and building damage. Unfortunately, large aftershocks sometimes compound a disaster following a mainshock. The ability to estimate possible aftershocks distributions might help mitigate their effects if the aftershock distributions are well understood. Several studies (Parsons et al. 2000; Lin and Stein 2004; Stein 1999) have discussed Coulomb stress transfer after earthquakes. Results show that seismicity corresponds significantly to the Coulomb stress change of the mainshock. Consequently, aftershocks usually locate in regions where Coulomb stress change has increased during the mainshock. These studies allow for the possibility of predicting aftershock distributions from stress transfer. Furthermore, if stress transfer studies can be conducted soon after a mainshock, the forecasting of possible aftershock distributions might be able to reduce the damage caused by large aftershocks.

In view of this possibility, we investigate several moderate to large inland Taiwan earthquakes with regard to their aftershock distributions and corresponding Coulomb stress change due to the mainshock. Stress change was calculated using a dislocation model obtained through strong motion waveform inversions for a finite-fault model. An accurate stress change pattern relies on a detailed understanding of the spatial slip distribution. However, the high-resolution fault dislocation model is usually rather time consuming for accurate Green's function calculations. When investigating the possibility of forecasting an aftershock distribution, it is necessary that stress change calculations can be conducted rapidly. Studies of the recent moderate to large earthquakes on Taiwan have produced a scaling law for earthquakes based on magnitude with average slip, rupture length and width (Ma and Wu 2001). According to the scaling law, first hand calculations on possible slip distribution of earthquakes may be more rapidly available. Following the model, stress change can then be soon calculated to obtain positive stress change regions for possible aftershock distribution. In this study, we first calculate stress change associated with earthquakes using well-determined spatial slip distributions along faults. We further examine the correlation between positive stress change regions and aftershock distribution. For the purposes of forecasting possible aftershock distribution, we compare the stress change pattern from the accurate slip distribution model and that from the homogenous slip model according to the developed scaling law. By comparison, we discuss the association of aftershocks with stress change and the possibility of rapid stress change calculations in forecasting aftershock distributions through the earthquake scaling law.

In this study, slip dislocations of several moderate to large earthquakes from the past ten years in the Taiwan area by $\mathrm{Ma}$ and $\mathrm{Wu}$ (2001) are used to calculate stress transfer conditions associated with aftershock distribution. Furthermore, we calculate changes in Coulomb stress by a homogeneous fault according to rupture length, width, displacement by magnitude of the earthquakes under consideration, the geometry of rupture planes using the scaling law developed by $\mathrm{Ma}$ and $\mathrm{Wu}$ (2001), and focal mechanisms which are available in a short time after earthquakes. Comparison of stress transfer associated with these fault models and aftershock distributions allows for the possibility of forecasting aftershock distribution through rapid stress change calculations following a mainshock. 


\section{SPATIAL SLIP MODEL AND METHODS}

We consider the spatial slip distribution model obtained by Ma and Wu (2001) for Coulomb stress change calculations. The spatial slip distribution was calculated using near-field strong motion waveforms for a finite-fault model. We call the model thus obtained a heterogeneous slip model. For a homogeneous slip fault model, the rupture length, width, and slip were established from the magnitude of the earthquakes according to the scaling law developed by $\mathrm{Ma}$ and $\mathrm{Wu}$ (2001). The locations and focal mechanisms of events were obtained through Central Weather Bureau, Taiwan, and Broadband Array in Taiwan for Seismology (BATS) which are available soon after the occurrence of earthquakes.

On the basis of the kinematic spatial slip distribution model, Coulomb stress change ( $\Delta \mathrm{CFF}$ ) of the Chi-Chi earthquake was calculated to examine stress transfer and stress triggering related to the occurrence of the aftershocks for optimal orientation plans (OOP, King et al. 1994), according to:

$$
\Delta C F F=\Delta \tau+\mu^{\prime} \Delta \sigma,
$$

where $\Delta \tau$ is the shear stress change, $\mu^{\prime}$ is apparent frictional coefficient after accounting for the pore fluid pressure effect, and $\Delta \sigma$ is the normal stress change (Toda et al. 1998; King et al. 1994). Usually $\mu^{\prime}$ is considered to be high for thrust faults (0.8). Ma et al. (2004) show that different values of $\mu^{\prime}$ have influence on the threshold for stress triggering, for the large static shear stress of the Chi-Chi earthquake, the influence of the values of $\mu^{\prime}$ on the pattern of stress change is modest. The direction and magnitude of regional stress might also have some influence over the pattern of stress change. Several studies (e.g., Seno 1977; Hu et al. 1996) show that the direction of regional stress in the Taiwan region is in a NW-SE direction, we consider regional stress with an angle of $302^{\circ}$ for our calculations. Regional stress in the direction of the stress axis of the Philippine Sea to the Eurasian Plates is considered. As discussed in King et al. (1994), the magnitude of regional stress relative to calculations of Coulomb stress change might have some bearing on the pattern of stress change close to the fault. Thus, stress change in off-fault regions is more reliable.

\section{RESULTS}

\subsection{Coulomb Stress Changes from Heterogeneous Slip Fault Models}

For this study, we first considered five earthquake sequences, namely the December 15, 1993 Da-Pu $\left(M_{L}=5.7\right)$; June 5, 1994 Nan-Ao $\left(M_{L}=6.2\right)$; July 17, 1998 Ruey-Li $\left(M_{L}=6.2\right)$; October 22, 1999 Chia-Yi $\left(M_{L}=6.4\right)$; and October 22, 1999 Chia-Yi-2 $\left(M_{L}=6.0\right)$ earthquakes as shown in Fig. 1. The 1999 Chi-Chi, Taiwan, earthquake was also examined. Due to its complex fault rupture, we discuss the Chi-Chi earthquake in a separate section. Table 1 shows the source parameters (origin time, location of hypocenters, and local magnitudes) of these events determined by-Central Weather Bureau Seismological Network (CWBSN). 
Heterogeneous slip fault models as shown in Fig. 2 were determined by waveform inversions for a finite-fault model from Taiwan Strong Motion Network (TSMN) by Ma and Wu (2001) and are used to calculate Coulomb stress change. The Coulomb stress changes for corresponding events are shown in Fig. 3. One-month aftershocks, which were located using the doubledifference earthquake location algorithm (Waldhauser and Ellsworth 2000), are also shown for comparison with Coulomb stress change patterns. Due to variation in stress changes at

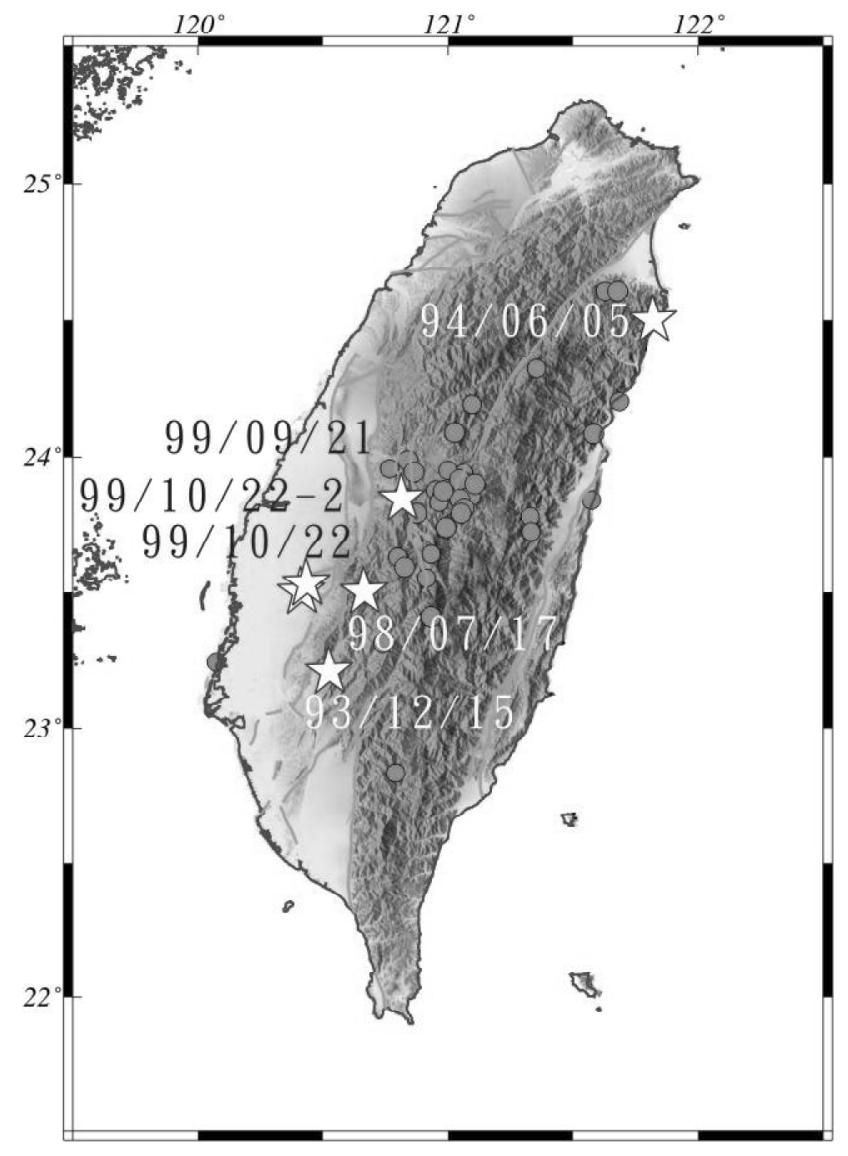

Fig. 1. Circles represent the distribution of earthquakes with $M_{L}>5.0$ since 1993 in the Taiwan area from Central Weather Bureau Seismogram Network (CWBSN) datum. Asterisks denote events with high aftershock activity to be discussed in relation to stress transfer and seismicity changes after earthquakes. 
depth for thrust type earthquakes, stress changes associated with the Da-Pu, Ruey-Li and ChiaYi earthquakes with aftershock seismicity within $3 \mathrm{~km}$ of each profile are given at various depths. Because the two Chia-Yi earthquakes occurred within one hour of one another, the Coulomb stress changes for these two events are considered simultaneously representing the final Coulomb stress change after October 22, 1999.

To compare stress change associated with the distribution of aftershocks, we do some statistical analysis of the number of aftershocks within a $0.5 \mathrm{~km} \times 0.5 \mathrm{~km} \times 0.5 \mathrm{~km}$ block. The percentage of aftershocks corresponding to Coulomb stress changes within the block is shown in Figs. 4a, b, c and d for the four earthquake sequences. Most of the aftershocks are located in areas where stress increased. Accordingly, about $88 \%, 55 \%, 96 \%$, and $76 \%$ of

Table 1. Source parameters and fault plane parameters of moderate events investigated in this study.

\begin{tabular}{|c|c|c|c|c|c|c|}
\hline \multicolumn{2}{|c|}{ Earthquake } & $\mathrm{Da}-\mathrm{Pu}$ & Nan-Ao & Ruey-Li & Chia-Yi & Chia-Yi-2 \\
\hline \multirow{6}{*}{ Origin Time } & Year & 1993 & 1994 & 1998 & 1999 & 1999 \\
\hline & Month & 12 & 6 & 7 & 10 & 10 \\
\hline & Day & 15 & 5 & 17 & 22 & 22 \\
\hline & Hour & 21 & 1 & 4 & 2 & 3 \\
\hline & Minute & 49 & 9 & 51 & 18 & 10 \\
\hline & Second & 43.1 & 30.09 & 14.96 & 556.8 & 17.5 \\
\hline \multirow{3}{*}{ Location } & Longitude $\left({ }^{\circ}\right)$ & 120.523 & 121.838 & 120.663 & 120.422 & 120.431 \\
\hline & Latitude $\left({ }^{\circ}\right)$ & 23.213 & 24.462 & 23.503 & 23.517 & 23.533 \\
\hline & Depth $(\mathrm{km})$ & 12.5 & 5.3 & 2.8 & 16.59 & 16.74 \\
\hline \multicolumn{2}{|c|}{ Magnitude $\left(\mathrm{M}_{\mathrm{L}}\right)$} & 5.7 & 6.2 & 6.2 & 6.4 & 6 \\
\hline \multirow{3}{*}{ Focal Mechanism } & Strike $\left(^{\circ}\right)$ & 200 & 87 & 45 & 180 & 45 \\
\hline & $\operatorname{Dip}\left({ }^{\circ}\right)$ & 48 & 81 & 50 & 42 & 90 \\
\hline & $\operatorname{Rake}\left(^{\circ}\right)$ & 84 & 8 & 110 & 56 & 0 \\
\hline \multirow{2}{*}{$\begin{array}{c}\text { Moment } \\
\text { Magnitude }\left(\mathrm{M}_{\mathrm{w}}\right)\end{array}$} & Wu and $\mathrm{Ma}, 2000$ & 5.66 & 6.28 & 5.85 & 6.16 & 5.87 \\
\hline & One segment & 5.7 & 6.19 & 6.19 & 6.34 & 5.99 \\
\hline \multirow{2}{*}{ Fault Length $(\mathrm{km})$} & Wu and $\mathrm{Ma}, 2000$ & 9 & 15 & 10 & 8 & 5 \\
\hline & One segment & 4.62 & 10.97 & 10.97 & 15.49 & 7.76 \\
\hline \multirow{2}{*}{ Fault Width (km) } & $\mathrm{Wu}$ and $\mathrm{Ma}, 2000$ & 7 & 13 & 8 & 7 & 4.5 \\
\hline & One segment & 4.55 & 7.7 & 7.7 & 9.51 & 6.24 \\
\hline \multirow{2}{*}{ Fault Area $(\mathrm{km} 2)$} & $\mathrm{Wu}$ and $\mathrm{Ma}, 2000$ & 63 & 195 & 80 & 56 & 22.5 \\
\hline & One segment & 21.05 & 84.49 & 84.49 & 147.33 & 48.46 \\
\hline \multirow{2}{*}{ Displacement (m) } & Wu and $\mathrm{Ma}, 2000$ & 0.259 & 0.567 & 0.307 & 1.27 & 1.17 \\
\hline & One segment & 0.234 & 0.436 & 0.436 & 0.559 & 0.34 \\
\hline
\end{tabular}


aftershocks for the $\mathrm{Da}-\mathrm{Pu}$, Nan-Ao, Ruey-Li, and Chia-Yi earthquake sequences, respectively, show association with positive stress changes. Apart from the Nan-Ao earthquake sequence, the other sequences show a greater than $75 \%$ association between aftershocks and positive stress changes, supporting the possibility on forecasting aftershock distributions from stress transfer due to a mainshock.

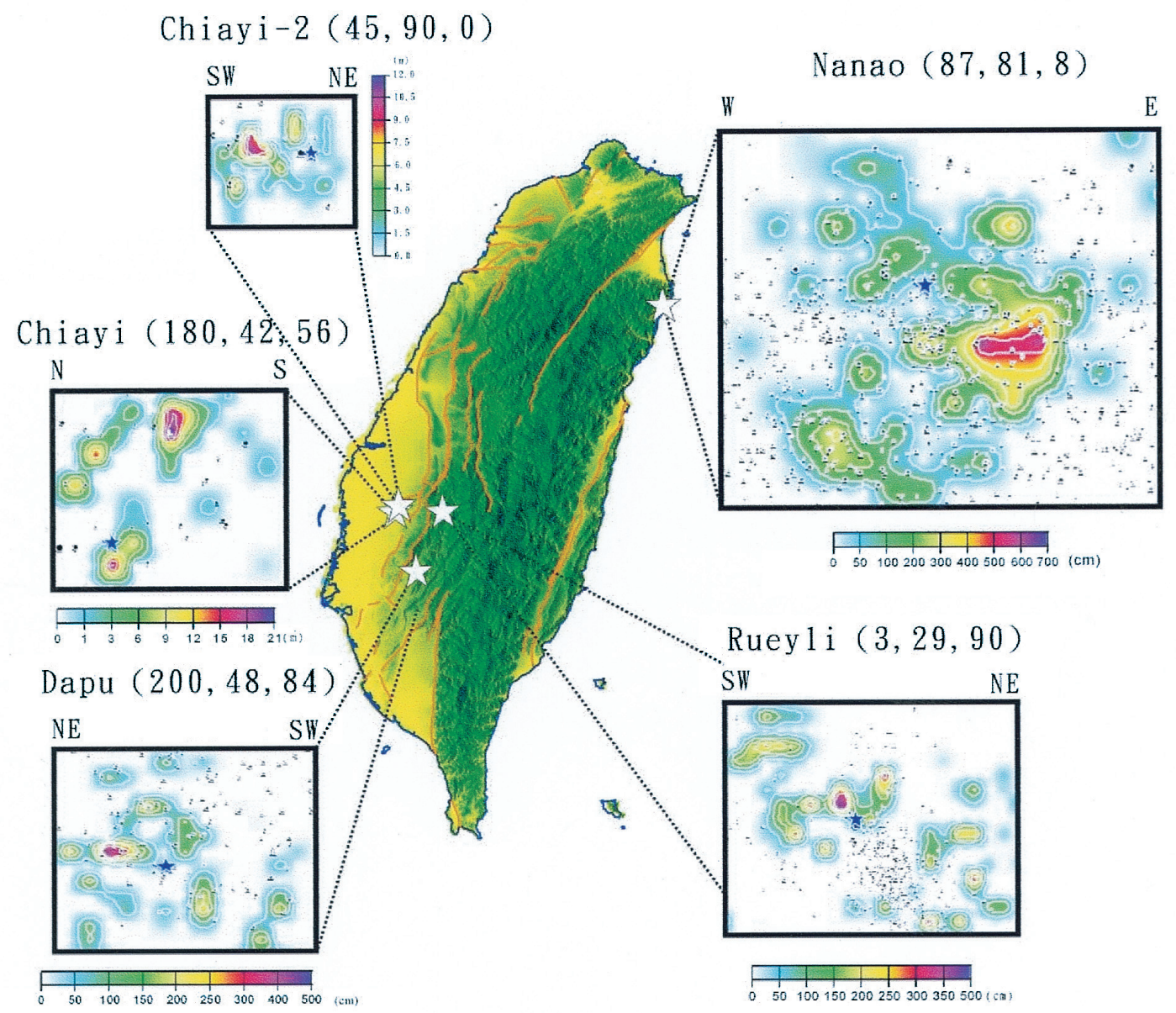

Fig. 2. Spatial slip dislocations models for Da-Pu, Nan-Ao, Chia-Yi, and ChiaYi-2, respectively, determined by waveform inversion using Taiwan Strong Motion Network (TSMN) data by Ma and Wu (2001). Above each Fig. represents strike, dip, and rake of the fault plane. Slip amounts are shown by the colored bar below each panel. The asterisks denote the hypocenters of the mainshocks. 


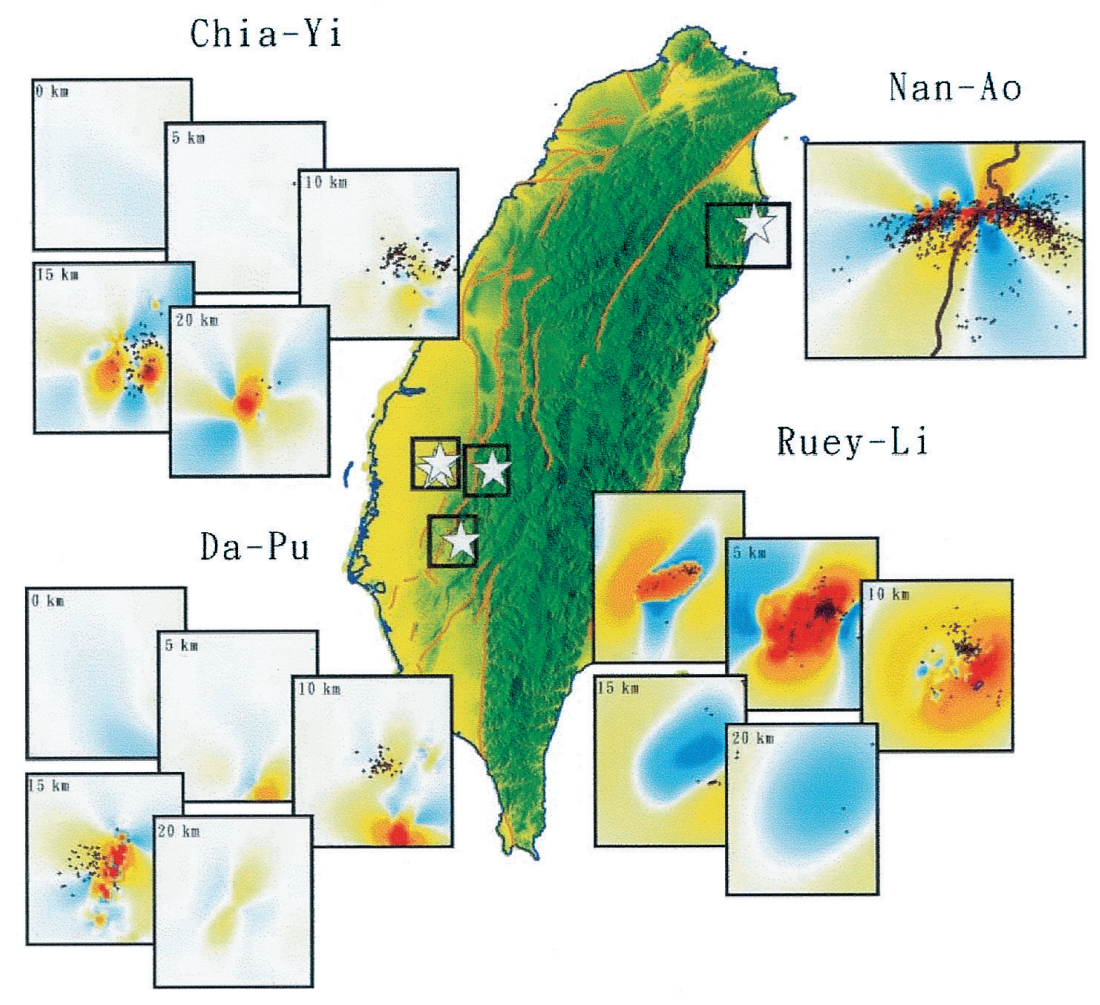

(Bar)

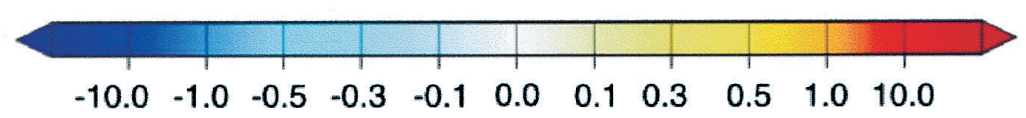

Fig. 3. Coulomb stress changes from heterogeneous fault models at various depths for comparison with one-month aftershock distributions (solid circles). Stress changes at various depths for the Da-Pu, Ruey-Li and Chia-Yi earthquakes are shown with aftershock seismicity within $3 \mathrm{~km}$ of each profile. The Coulomb stress changes of these two Chia-Yi events are considered simultaneously to represent the Coulomb stress change after October 22, 1999. Due to the vertical strike-slip mechanism of Nan-Ao earthquake, the Coulomb stress change is shown for depth at the surface. The solid box indicates the corresponding area for stress change calculations. The asterisks denote the hypocenters of the mainshocks. The amount of stress change is shown by the colored bar. 
(a)

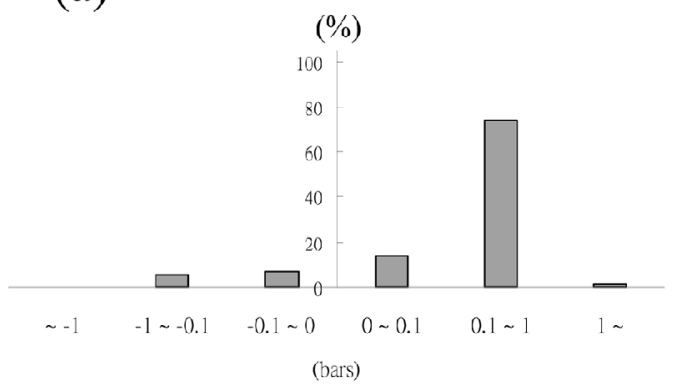

(b)

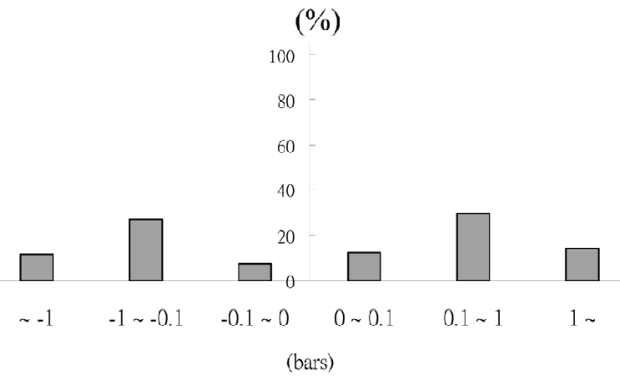

(c)

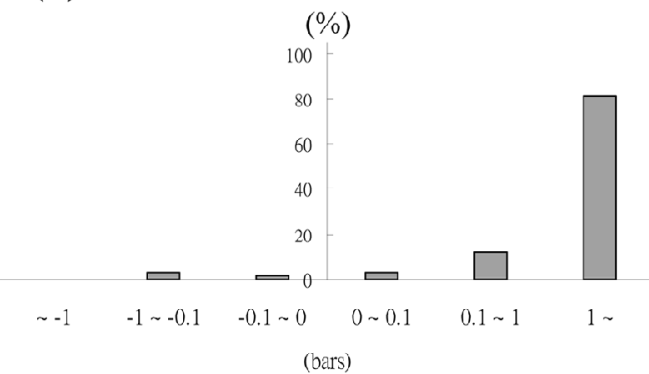

(d)

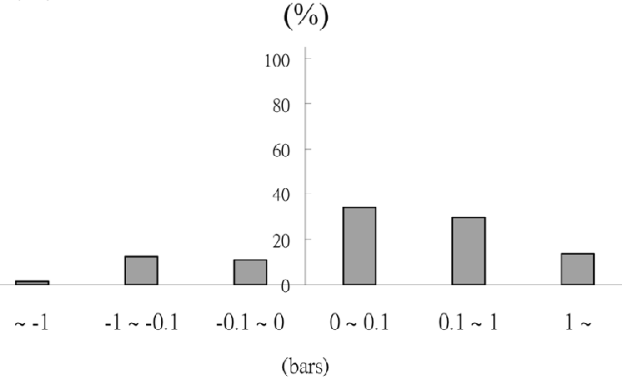

Fig. 4. The percentage of aftershocks corresponding to the Coulomb stress changes within a $0.5 \mathrm{~km} \times 0.5 \mathrm{~km} \times 0.5 \mathrm{~km}$ block for (a) Da-Pu, (b) Nan-Ao, (c) Ruey-Li, and (d) Chia-Yi, respectively, derived from the heterogeneous fault models.

\subsection{Coulomb Stress Changes from Homogenous Slip Models}

Forecasting aftershock distributions is not possible without having a rapid understanding of an earthquake's fault slip model; however, a detailed fault slip distribution model is usually very time consuming due to the complexity involved in performing Green's function calculations. Consequently, we investigate Coulomb stress change via a homogenous fault model using the fault scaling law obtained by $\mathrm{Ma}$ and $\mathrm{Wu}$ (2001) for inland Taiwan earthquakes. According to the scaling law homogenous fault slip distribution can be determined as soon as the location and focal mechanism of an earthquake become available. Table 1 gives rupture length, width, and average amount of slip on the fault corresponding to the earthquake magnitudes as estimated using the scaling law Ma and Wu (2001) obtained. The empirical relationships of those parameters are given below: 


$$
\begin{aligned}
& \mathrm{Mw}=(1.32 \pm 0.122) \log (\mathrm{L})+(4.817 \pm 0.132), \\
& \mathrm{Mw}=(0.82 \pm 0.071) \log (\mathrm{A})+(4.61 \pm 0.141), \\
& \mathrm{Mw}=(1.83 \pm 0.39) \log (\mathrm{D})+(6.85 \pm 0.23),
\end{aligned}
$$

where $M_{W}$ is the moment magnitude, $\mathrm{L}$ is the rupture length in $\mathrm{km}$; $\mathrm{A}$ is the rupture area in $\mathrm{km}^{2}$; and D is average slip in meters. The empirical correlation of $M_{L}$ to $M_{W}$ as,

$$
M_{W}=(0.99 \pm 0.138) M_{L}+(0.052 \pm 0.84)
$$

was used.

For homogeneous fault model calculations, we assume the mainshock is located at the center of the fault plane. Corresponding Coulomb stress changes for the events under consideration were thus obtained and are shown in Fig. 5. Statistical percentages relating aftershocks to Coulomb stress change within block of $0.5 \mathrm{~km} \times 0.5 \mathrm{~km} \times 0.5 \mathrm{~km}$ are shown in Fig. $6 \mathrm{a}, \mathrm{b}$ and $\mathrm{c}$ for the four earthquake sequences, respectively. Most aftershocks are located in the increased stress regions. Overall, about $84 \%, 58 \%, 81 \%$, and $100 \%$ of the aftershocks for the Da-Pu, Nan-Ao Ruey-Li, and Chia-Yi earthquake sequences, respectively, are located in positive stress change regions. The correlation between results obtained using homogeneous slip fault models and the heterogeneous slip fault models discussed in Section 3.1, suggests that it is possible to use rapid stress change calculations based on homogenous slip models using scaling law to forecast aftershock distributions.

\subsection{Case Study of the 1999 Chi-Chi Earthquake}

The previous study shows that, in the case of moderate earthquakes, it is possible to use rapid stress change calculations based on homogenous fault models derived from the scaling law to forecast aftershock distributions. The September 21, 1999 Chi-Chi earthquake $\left(M_{L}=7.3\right)$ produced complex fault geometry and was accompanied by many aftershocks including several aftershocks of magnitude greater than 6. It is important to know whether the rapid stress change calculations discussed previously are valid for the large complicated events such as the Chi-Chi earthquake.

Fault ruptured during the Chi-Chi earthquake was composed of three segments, an 80$\mathrm{km}$-long north-south segment, a 20-km-long segment to the southwest and a 30-km-long segment to the northeast. Each fault segment has a width of $40 \mathrm{~km}$ and a dip of $30^{\circ}$ to the southeast. We consider three stages in Coulomb stress change calculations for this large event. First we consider spatial slip distribution as determined by Ji et al. (2003) and shown in Fig. 7. This model was obtained using strong motion and GPS data. The results compare favorably with other spatial slip distribution models (e.g., Ma et al. 2001) and show good prediction in wave- 


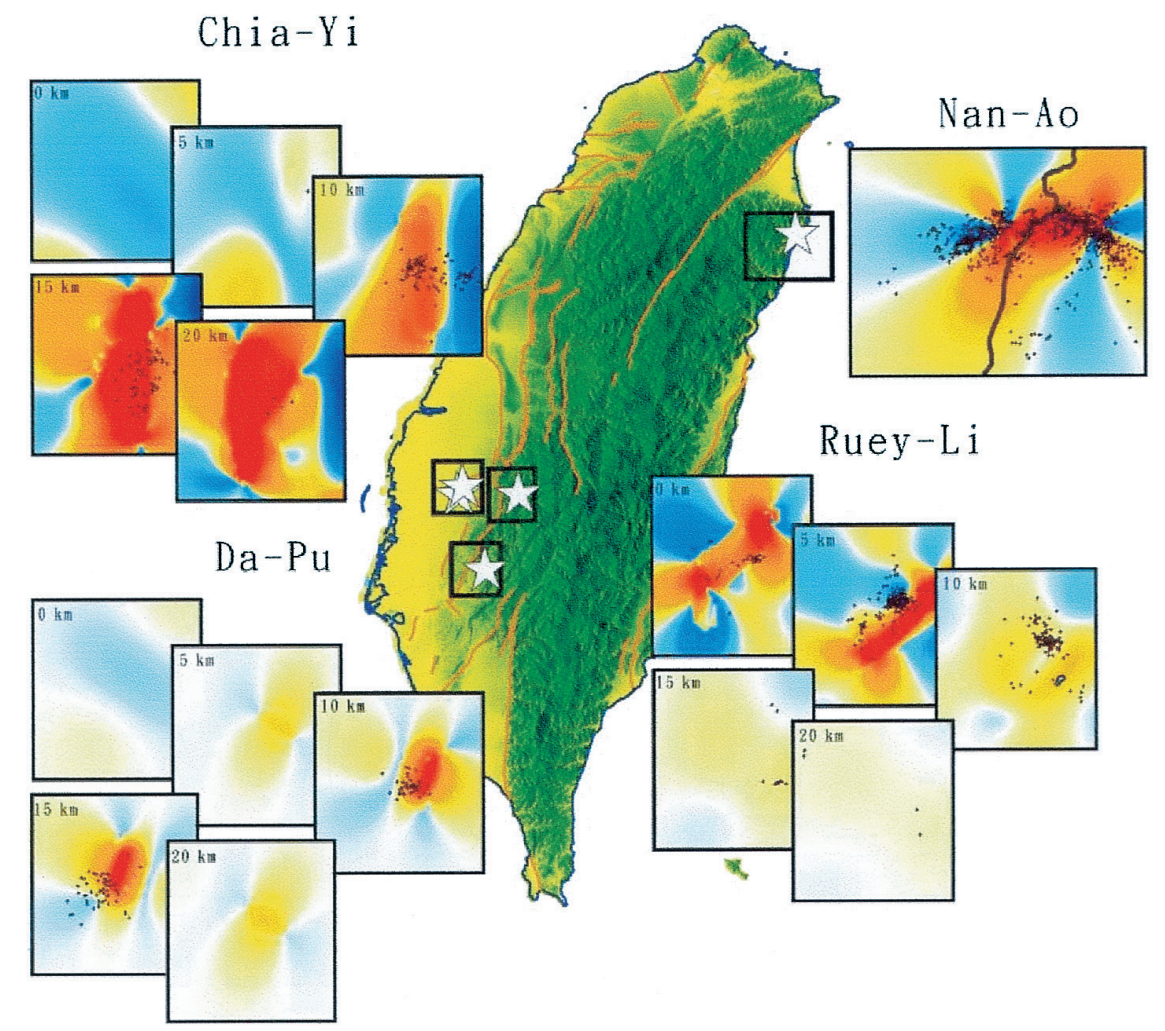

(Bar)

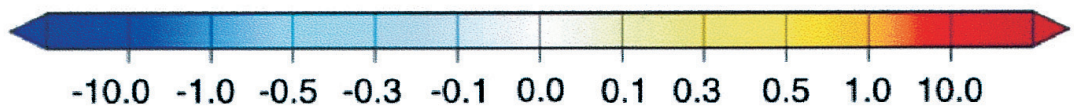

Fig. 5. The Coulomb stress changes by homogeneous fault models at various depths for comparison with one-month aftershock distributions (solid circles). Stress changes at various depths for the Da-Pu, Ruey-Li and Chia-Yi earthquakes are shown with aftershock seismicity within $3 \mathrm{~km}$ of each profile. The Coulomb stress changes of the two Chia-Yi events are considered simultaneously to represent the Coulomb stress change after October 22, 1999. The solid box indicates the corresponding area for the stress change calculations. The asterisks denote the hypocenters of the mainshocks. The amount of stress change is shown by the colored bar. 
forms to the teleseismic data. The second stage involves Coulomb stress change calculations corresponding to homogenous slip models for the three segments. The average slip of each segment is listed in Table 2. The third stage examines one fault segment with homogenous fault slip. The fault geometry regarding fault length, width and amount of slip was estimated using the scaling law derived by $\mathrm{Ma}$ and $\mathrm{Wu}$ (2001). The fault parameters were then estimated using the focal mechanism and magnitude, and are listed in Table 2.

In order to examine Coulomb stress change in relation to aftershock distribution, we considered aftershocks based on a 3-month window post the September 21 earthquake. Comparisons of aftershocks with regard to Coulomb stress changes for the three stages discussed are shown in Figs. 8a, b and c, respectively. For statistical purposes, the number of aftershocks within a $1 \mathrm{~km} \times 1 \mathrm{~km} \times 1 \mathrm{~km}$ block was estimated. The percentage of aftershocks within each block corresponding to Coulomb stress change is shown in Figs. 9a, b and c. Overall, about $68 \%, 60 \%$, and $76 \%$ of aftershocks are located in regions of positive changes in stress for the heterogeneous slip, three-segment, and single-segment models, respectively. This sug-

(a)

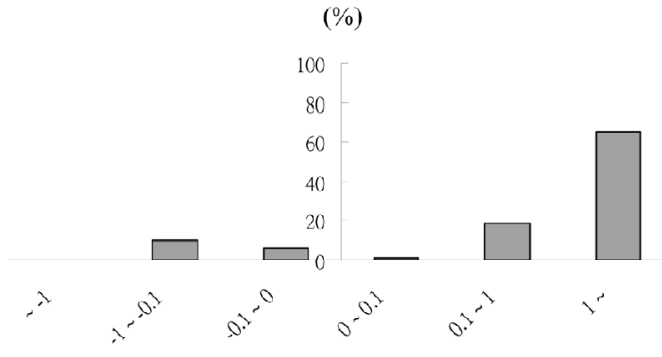

(b)

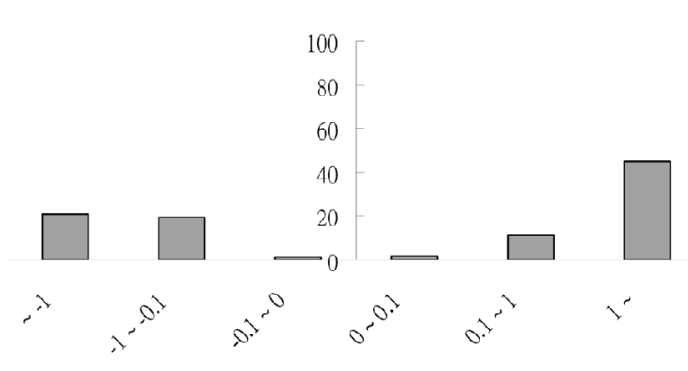

(c)

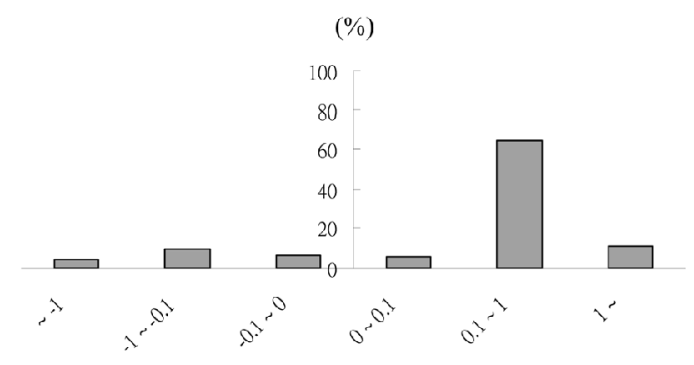

(d)

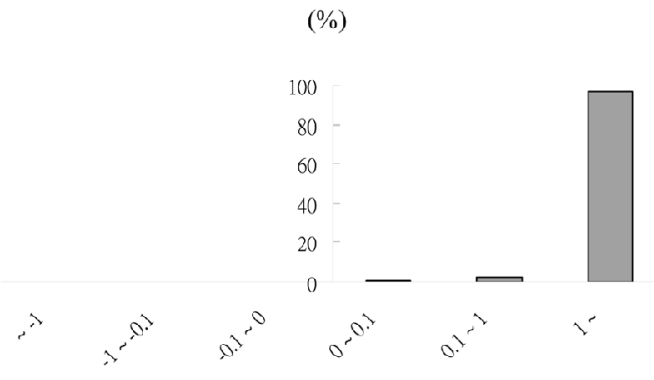

Fig. 6. The percentage of aftershocks corresponding to Coulomb stress changes within a $0.5 \mathrm{~km} \times 0.5 \mathrm{~km} \times 0.5 \mathrm{~km}$ block for (a) Da-Pu, (b) Nan-Ao, (c) Ruey-Li, and (d) both of Chia-Yi and Chia-Yi-2, respectively, derived from the homogeneous fault models. 


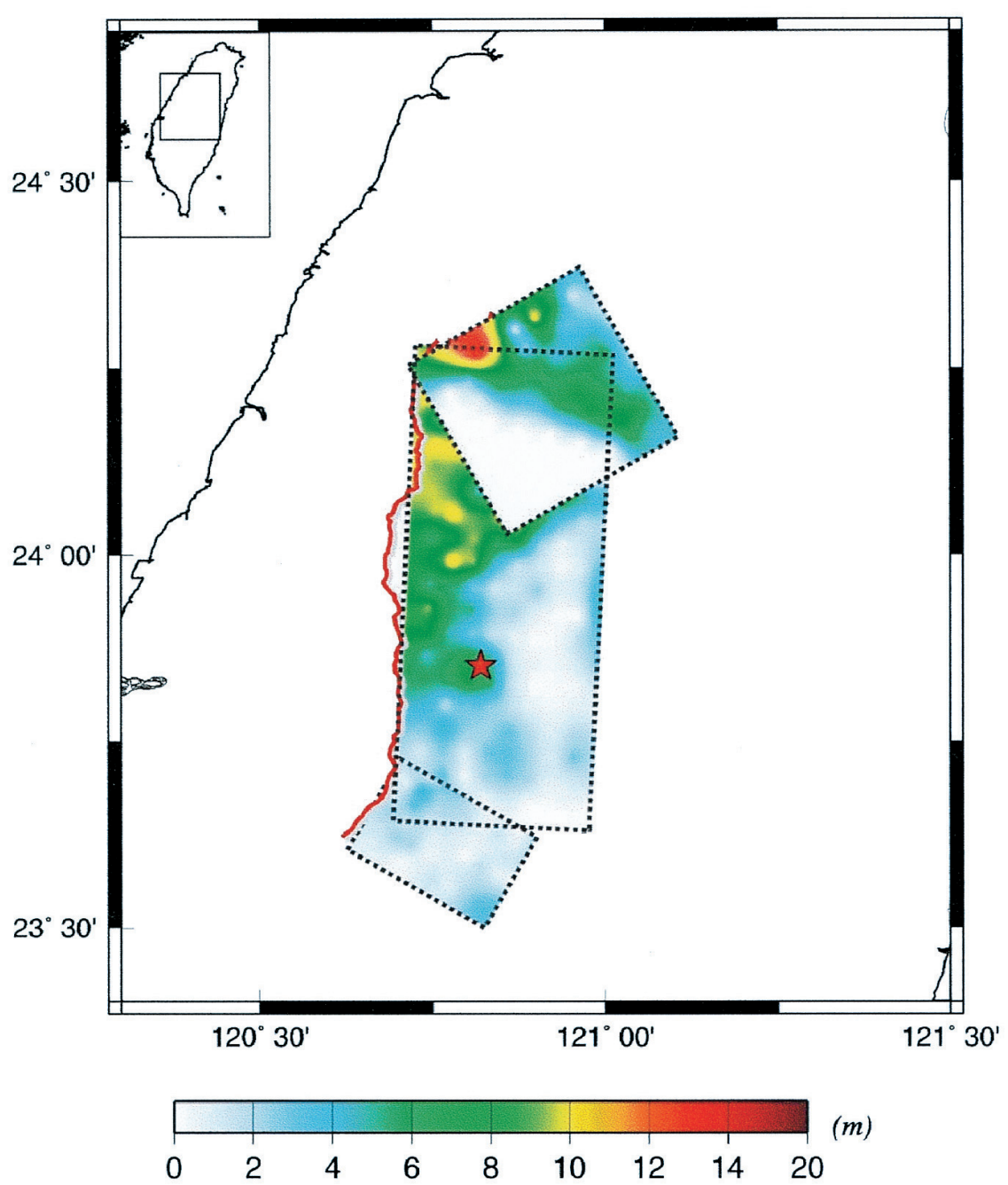

Fig. 7. Slip model for the Chi-Chi earthquake by Ji et al. (2003). Red line denotes the surface rupture of Chelungpu fault. This model presents three fault segments: the main, 80-km-long north-south segment, a 20-km-long segment to the southwest and a $30-\mathrm{km}$-long segment to the northeast. Each fault segment has a width of $40 \mathrm{~km}$ and a dip of $30^{\circ}$ to the southeast. The amount of slip is shown by the colored bar. The asterisk indicates the hypocenter of the Chi-Chi earthquake. 
Table 2. Fault parameters description for Chi-Chi earthquake slip models for three-segments and single-segment homogenous faults used in this study. For displacement values, positive denotes right-lateral and thrust on shear and dip components, respectively.

\begin{tabular}{|c|c|c|c|c|c|}
\hline \multicolumn{2}{|c|}{} & \multicolumn{3}{|c|}{ Three Segments } & \multirow{2}{*}{ One Segment } \\
\cline { 3 - 5 } & Main & North & South & \\
\hline $\begin{array}{c}\text { Fault Plane } \\
\text { Geometry }\end{array}$ & Strike $\left(^{\circ}\right)$ & 3 & 60 & 30 & 3 \\
\cline { 2 - 5 } & Dip $\left(^{\circ}\right)$ & 30 & 30 & 30 & 29 \\
\hline \multicolumn{2}{|c|}{ Fault Length $(\mathrm{km})$} & 80 & 30 & 20 & 73.308 \\
\hline \multicolumn{2}{|c|}{ Fault Width $(\mathrm{km})$} & 40 & 40 & 40 & 24.5316 \\
\hline \multirow{2}{*}{$\begin{array}{c}\text { Displacemen } \\
\mathrm{t}(\mathrm{m})\end{array}$} & Shear & -1.766 & 1.62 & 0.736 & 0 \\
\cline { 2 - 5 } & Dip & 2.599 & 1.986 & 1.044 & 1.716 \\
\hline
\end{tabular}

gests that even for complex fault rupture, it is still possible to use rapid stress change calculations on the basis of homogenous slip models and scaling law to forecast aftershock distribution.

\section{DISCUSSIONS AND CONCLUSIONS}

Coulomb stress changes associated with earthquakes influence the occurrence of future earthquakes. The magnitude of an earthquake yields significant differences in Coulomb stress changes. In order to understand the influence of Coulomb stress change on sub-sequence events, six $M>6$ Chi-Chi aftershocks (Table 3) were taken into account to compare resultant stress changes from the mainshock alone. (Fig.10) Due to significantly different magnitudes between mainshocks and aftershocks, the order of Coulomb stress change is significantly different. Comparison of stress change patterns associated with the mainshock, and six aftershocks and the mainshock only, disregarding the regions closest to the hypocenters of the aftershocks, reveals stress change patterns that are in general very similar. This result indicates that the influence of the sub-sequence earthquakes on stress change can be ignored.

For Coulomb stress change calculations, it is necessary to consider the mechanism associated with receiver faults. Due to the complicated tectonic structure of Taiwan, the focal mechanisms of the mainshock and aftershocks often result from different rupture plans. For example, according to the focal mechanism of the mainshock and its aftershock distribution, the rupture of Ruey-Li mainshock resulted from a northeast-southwestern striking plane with eastern dip. The possible faults associated with this earthquake are either the Tachienshan fault or Chukou fault (Chan and Ma 2004). According to aftershock distributions and their focal mechanisms, however, the aftershocks can be classified into two categories: thrust and strike-slip types (Chen 2003). The same patterns were also observed for the $1993 \mathrm{Da}-\mathrm{Pu}$ and the two 1999 
(a)
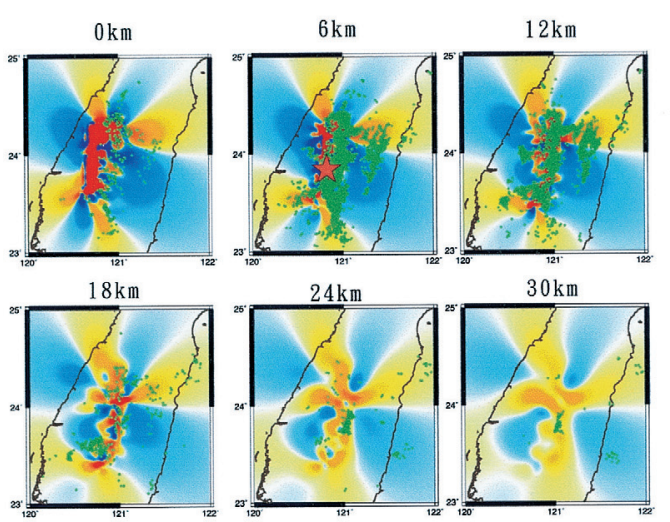

(b)
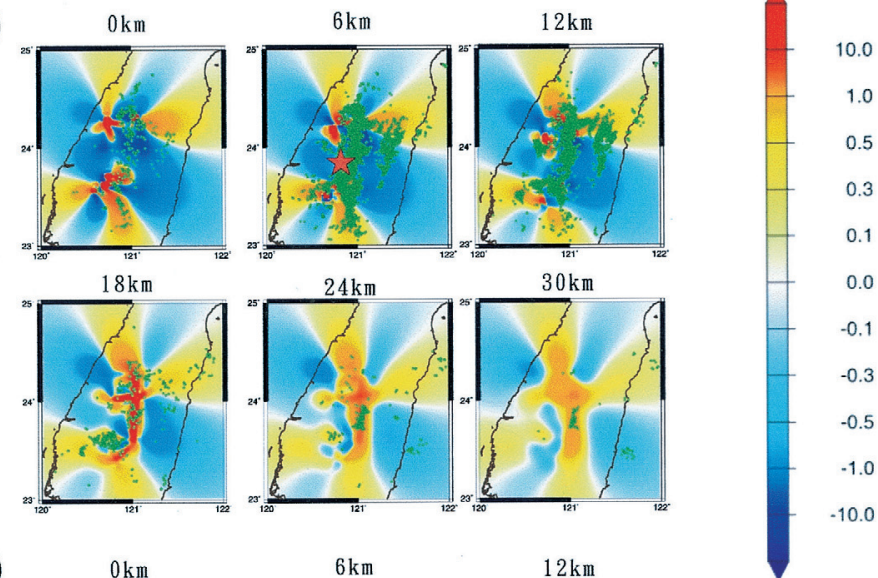

(c)

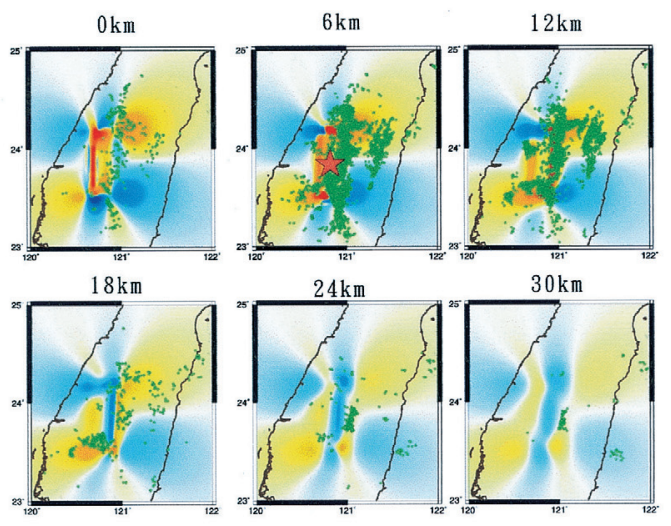

Fig. 8. Changes of Coulomb failure stress based on (a) the heterogeneous slip model by Ji et al. (2003), (b) the three-segment model, and (c) the onesegment model. The three-month aftershocks (green circles) are considered. The amount of Coulomb stress change is shown by the colored bar. 
(a)

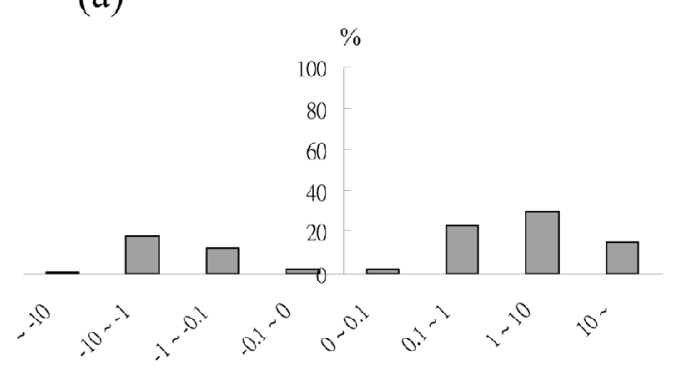

(b)

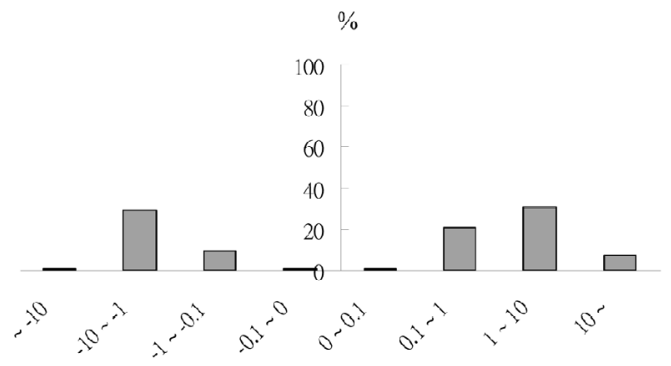

(c)

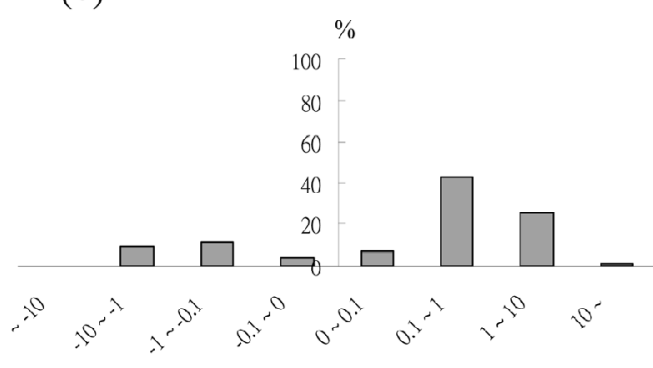

Fig. 9. The percentage of aftershocks corresponding to Coulomb stress changes within a $1 \mathrm{~km} \times 1 \mathrm{~km} \times 1 \mathrm{~km}$ block for (a) the model by Ji et al. (2003), (b) the three-segment model, and (c) the one-segment model.

Chia-Yi earthquakes. They all display aftershocks having various focal mechanisms to the mainshock. The differences in aftershock focal mechanisms to the mainshock raise questions about associated mainshock Coulomb stress changes and the aftershocks under investigation. Fortunately, our study shows that by adopting the concept of optimum orientation planes developed by King et al. (1994), Coulomb stress changes show very positive correlation to the distribution of aftershocks. Although the focal mechanisms of some aftershocks might be different from that of the mainshock, most aftershocks follow the concept of optimum orientation planes. Thus, reasonable correlation to aftershock distribution is yielded with respect to positive Coulomb stress changes without taking the complicated geological settings of Taiwan into account.

For large earthquake such as the 1999 Chi-Chi, Taiwan, earthquake, which had a complicated ruptured fault of nearly $100 \mathrm{~km}$ in length complex focal mechanisms associated with aftershocks are yielded. Our study shows that for this large earthquake, it is necessary to take into account possible variations in stress fields for thrust, strike-slip, and normal type focal mechanisms to achieve more precise estimates of aftershocks to stress change. However, our results also show that the stress change calculations for optimum orientation planes can also explain most aftershocks. Large earthquakes like the Chi-Chi earthquake are usually accompanied by many large aftershocks over a long time period. 
The correlation between Coulomb stress changes and aftershock distribution strongly suggests the possibility of forecasting aftershock distributions from Coulomb stress changes. To make this possible, rapid stress change calculations are required after an earthquake. Coulomb stress change calculations based on homogenous fault models using scaling law show similar stress patterns to those derived from heterogeneous slip fault models using waveform inversion in the case of Taiwan. This implies that changes in Coulomb stress are generally dominated by the orientations of fault plane geometries and slip directions rather than the detailed pattern of slip distribution. However, the scale of stress change due to homogenous fault calculations is usually greater than that from heterogeneous slip distributions. This is because homogeneous fault models bring a broader distribution of slip rather than localized slip on asperities as derived from waveform inversion. In addition moment magnitude determined from a scaling law might have a larger estimate producing broader stress distribution (Table1). These characteristics do not influence strongly the correlation between aftershock distribution and positive stress change. Even though the amount of stress change from these two models is different, we did not discuss the amount of stress change and occurrence of the aftershocks. Such a discussion is still difficult since most studies (Ma et al. 2004) show there is no direct correlation between the degree of stress change and the amount of aftershocks.

For the 1999 Chi-Chi earthquake, although stress change patterns for the detailed slip distribution, three-segment homogenous fault, and one-segment homogenous fault models, are slightly different from each other, the most prominent features of aftershock distribution can be explained by all three fault models, namely the region near the Chia-Yi earthquake, and the southern linear extension of the aftershock near southern end of the Chelungpu fault. More than $60 \%$ of aftershocks are located in areas that correspond to Coulomb stress increases for

Table 3. Source parameters and fault plane parameters of six Chi-Chi aftershocks determined by Chi and Dreger (2003)

\begin{tabular}{|c|c|c|c|c|c|c|c|}
\hline \multicolumn{2}{|c|}{ Aflershock Number } & 1 & 2 & 3 & 4 & 5 & 6 \\
\hline \multirow{6}{*}{ Origin Time } & Year & 1999 & 1999 & 1999 & 1999 & 1999 & 1999 \\
\hline & Month & 9 & 9 & 9 & 9 & 9 & 10 \\
\hline & Day & 20 & 20 & 20 & 22 & 25 & 22 \\
\hline & Hour & 17 & 18 & 21 & 0 & 23 & 2 \\
\hline & Minute & 57 & 3 & 46 & 14 & 52 & 18 \\
\hline & Second & 15.31 & 41.16 & 37.49 & 40.77 & 49.51 & 56.93 \\
\hline \multirow{3}{*}{ Location } & Longitude $\left(^{\circ}\right)$ & 121.01 & 120.86 & 120.82 & 121.08 & 121.01 & 120.54 \\
\hline & Latitude $\left({ }^{\circ}\right)$ & 23.94 & 23.81 & 23.6 & 23.81 & 23.87 & 23.53 \\
\hline & Depth $(\mathrm{km})$ & 8 & 8 & 18 & 10 & 16 & 16 \\
\hline \multicolumn{2}{|c|}{ Magnitude $\left(\mathrm{M}_{\mathrm{w}}\right)$} & 5.8 & 6.2 & 6.2 & 6.2 & 6.3 & 6.1 \\
\hline \multirow{3}{*}{ Focal Mechanism } & Strike $\left(^{\circ}\right)$ & 200 & 0 & 330 & 165 & 5 & 20 \\
\hline & $\operatorname{Dip}\left({ }^{\circ}\right)$ & 41 & 10 & 89 & 70 & 30 & 75 \\
\hline & Rake $\left(^{\circ}\right)$ & 78 & 80 & 15 & 100 & 100 & 90 \\
\hline
\end{tabular}


(a)
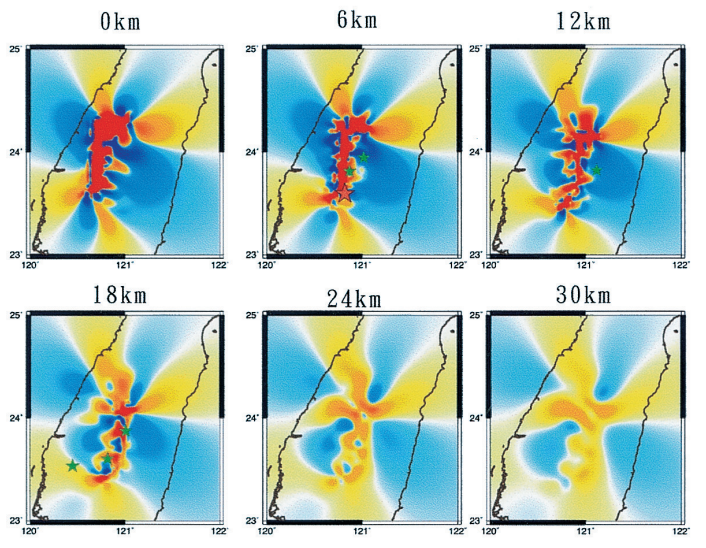

(b)
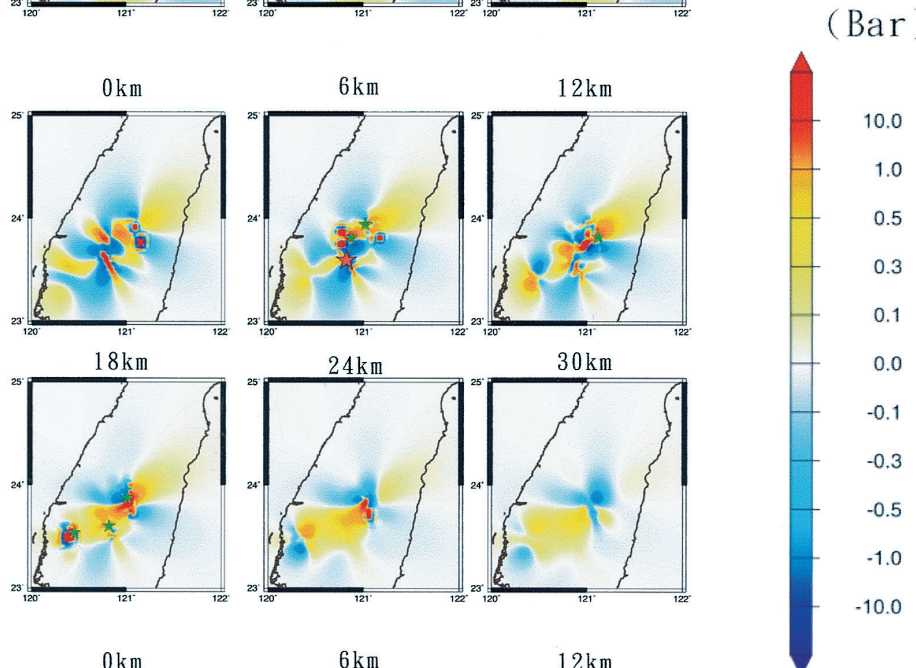

(c)
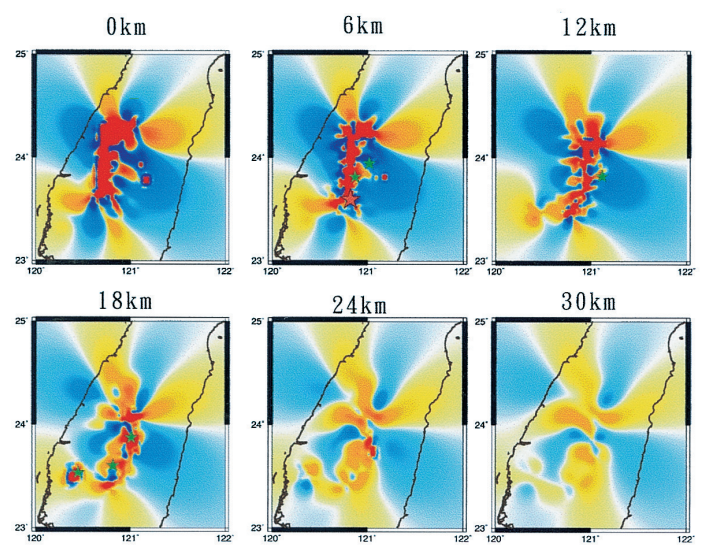

Fig.10. Coulomb stress change by (a) the Chi-Chi mainshock, (b) six $M>6$ aftershocks, and (c) a combination of the mainshock and six $M>6$ aftershocks. 
the three-segment and single-segment homogenous models. This also suggests that it is possible to use a homogenous single-segment fault model to perform rapid stress change calculations for forecasting aftershock distributions. Of course, stress change calculations can be updated according to detailed slip distribution fault models to give more precise estimations of aftershock distributions. Considering the earthquakes being investigated our study indicates that aftershock distributions caused by moderate to large earthquakes can be forecast using Coulomb stress change calculations for optimum oriented planes. In addition, reliable rapid stress change calculations are possible based on homogenous fault models derived from the earthquake scaling law of Ma and $\mathrm{Wu}$ (2001). Thus, once location, magnitude and focal mechanisms of earthquakes become available, the stress change calculation can be carried out to provide information on possible aftershock distributions. Calculation can be further updated according to detailed slip distributions allowing for more precise information regarding aftershock distributions.

\section{REFERENCES}

Chan, C. H. and K. F. Ma, 2004: Association of Five Moderate-Large Earthquakes to the Faults in Taiwan. TAO, 15, 1-14.

Chi, W. C. and D. Dreger, 2002: Seismic Hazard Mitigation and Crustal Deformation: results from finite source process of six $M_{W}>5.8$ Chi-Chi, Taiwan aftershocks. J. Geophys. Res., 29, no. 14, doi: 10,1029/2002GL015237.

Chen, C. H., W. H. Wang, T. L. Teng, 2003: Tectonic Implications of 1998, Ruey-Li, Taiwan, Earthquake Sequence. TAO, 14, 27-40.

Hu, J. C., J. Angelier, J. C. Lee, H. T. Chu, and D. Byrne, 1996: Kinematics of convergence, deformation and stress distribution in the Taiwan collision area: 2-D Finite-element numerical modeling. Tectonophys., 255, 243-268.

Ji, C., D. V. Helmerger, D. J. Wald, K. F. Ma, 2003: Slip history and dynamic implications of the 1999 Chi-Chi, Taiwan, earthquake.J. Geophys. Res., 108, B9, 2412, doi:10. 1029/ $2002 J B 001764$.

King, G. C. P., R. S. Stein, and J. Lin, 1994: Static stress changes and the triggering of earthquakes. Bull. Seis. Soc. Amer., 84, 935-953.

Lin, J. and R. S. Stein, 2004: Stress triggering in thrust and subduction earthquakes, and stress interaction between the southern San Andreas and nearby thrust and strike-slip faults. J. Geophys. Res., 109, B02303, doi:10.1029/2003JB002607.

Ma, K. F., J. Mori, S. J. Lee, and S. B. Yu, 2001: Spatial and temporal distribution of slip for the 1999 Chi-Chi, Taiwan earthquake. Bull. Seis. Soc. Am., 91, 1-19.

Ma, K. F. and S. I. Wu, 2001: Quick slip distribution determination of moderate to large inland earthquakes using near-source strong motion waveforms. Earthquake Engin. and Earthquake Seism., 3, 1-10.

Ma, K. - F., C. - H. Chan, and R. S. Stein, 2004: Earthquake triggering and Fault interaction in a thrust system, submitted to J. Geophys. Res.. 
Parsons, T., 2002: Global observation of Omori-law decay in the rate of triggered earthquakes: Large aftershocks outside the classical aftershock zone.J. Geophys. Res., 107, 2199, doi:10.1029/2001JB0006462.

Seno, T, 1977: The instantaneous rotation vector of the Philippine Sea Plate relative to the Eurasian Plate. Tectonophys., 42, 209-226.

Stein, R. S., 1999: The role of stress transfer in earthquake occurrence. Nature, 402, 605-609.

Toda, S., R. S. Stein, P. A. Reasenberg, J. H. Dieterich, and A. Yoshida, 1998: Stress transferred by the $M_{W}=6.9$ Kobe, Japan, shock: Effect on aftershocks and future earthquake probabilities. J. Geophys. Res., 103, 24543-24565.

Waldhauser, F., W. L. Ellsworth, 2000: A Double-difference earthquake location Algorithm: method and application to the northern Hayward fault, California. Bull. Seism. Soc. Am., 90, 1353-1368. 